\title{
PERENCANAAN SISTEM PENYEDIAAN AIR BERSIH DI KECAMATAN BELITANG KABUPATEN SEKADAU PROVINSI KALIMANTAN BARAT \\ Pandi M. Pugel ${ }^{1)}$ Kartini $^{2)}$ Laili Fitria $^{1)}$ \\ 1) Program Studi Teknik Lingkungan Jurusan Teknik Sipil Fakultas Teknik Universitas Tanjungpura, Pontianak \\ 2) Program Studi Teknik Sipil Jurusan Teknik Sipil Fakultas Teknik Universitas Tanjungpura, Pontianak Email : pandimpugel@yahoo.co.id
}

\begin{abstract}
ABSTRAK
Kecamatan Belitang memiliki sumber air baku yang melimpah, namun sampai saat ini belum tersedia fasilitas sarana sistem penyediaan air bersih. Oleh karena itu, perlu dilakukan perencanaan sistem penyediaan air bersih. Tujuan dari perencanaan ini untuk mengetahui aspek kualitas, kuantitas, kontinuitas air baku dan merencanakan sistem penyediaan air bersih di Kecamatan Belitang seperti merencanakan intake, pipa transmisi dan bangunan Instalasi Pengolahan Air (IPA). Metode yang digunakan yaitu dengan penyebaran kuesioner untuk mengetahui kondisi masyarakat, pengambilan sampel air, survei topografi menggunakan GPS. Hasil analisis yang didapatkan yaitu analisis ketersediaan air baku dengan metode Mock dimana sebelumnya didapatkan hasil evapotranspirasi kemudian cari debit untuk selanjutnya dilakukan perhitungan debit andalan 99\% dengan cara Weibull, analisis kebutuhan air bersih domestik dan non domestik penduduk Kecamatan Belitang selama 20 tahun, analisis kualitas air baku dengan cara pengujian sampel air secara in-situ dan ex-situ. Hasil uji kualitas, direncanakan sistem penyediaan air bersih untuk Kecamatan Belitang meliputi perencanaan intake, pipa transmisi dan bangunan Instalasi Pengolahan Air (IPA). Berdasarkan hasil uji kualitas air baku ada beberapa parameter yang tidak sesuai dengan baku mutu. Perlu dilakukan pengolahan untuk menyesuaikan dengan baku mutu air bersih yaitu parameter TSS, pH, Nitrat sebagai N, dan Besi. Hasil uji tersebut sistem pengolahan yang digunakan yaitu koagulasi, flokulasi, sedimentasi, filtrasi dan desinfeksi. Total kebutuhan air bersih pada jam puncak penduduk Kecamatan Belitang Tahun 2034 sebesar $0,03 \mathrm{~m}^{3} /$ detik atau 30 liter/detik. Debit yang didapatkan dari perhitungan debit andalan probabilitas $99 \%$ sebesar $6,076 \mathrm{~m}^{3} /$ detik dan hasil debit terukur dilapangan sebesar $17,07 \mathrm{~m}^{3} /$ detik. Jenis intake yang digunakan yaitu Floating Intake. Rencana pipa transmisi dari intake ke bangunan IPA menggunakan satu jalur pengaliran dengan panjang pipa yang direncanakan 150 meter dan berdiameter $200 \mathrm{~mm}$ dengan pipa yang digunakan yaitu pipa HDPE. Jenis bak koagulasi yang digunakan yaitu tipe hidrolis dengan terjunan dan dimensi bak 1,2 x 1,2 × 1,2 m. Bak flokulasi didesain menggunakan sumber energi gravitasi berupa saluran berbelok-belok yang berbentuk vertikal dan demensi bak $6 \times 2 \times 3 \mathrm{~m}$. Bak sedimentasi berjumlah 1 buah dengan dimensi bak 12,7 x 4,2 × $3 \mathrm{~m}$. Filter yang digunakan saringan pasir cepat dengan dimensi bak 3,4 × 1,7 x $2 \mathrm{~m}$. Desinfektan yang digunakan adalah kaporit untuk dimensi bak desinfeksi 1,7 x 1,6 x 1,6 m. Kapasitas reservoir air bersih yaitu 518,4 $\mathrm{m}^{3}$ dengan dimensi 13,2 × $13 \times 3 \mathrm{~m}$.
\end{abstract}

Kata Kunci: Air Bersih, Kecamatan Belitang, Ketersediaan Air, Kualitas Air.

\section{ABSTRACT}

The District of Belitang have abundant sources of raw water but until now there has been no facility of clean water supply system. Therefore, it is necessary to plan clean water supply system. The purpose of planning the clean water supply system is to determine the aspects of quality, continuity of raw water and planning clean water supply system in the District of Belitang as planned intake, pipeline transmission and Instalasi Pengolahan Air building. The method is used is by distributing questionnaires to determine the condition of the civil community, and taking water samples topographic surveys by using GPS. Analytical results obtained by an analysis of the availability of raw water with Mock method which previously showed evapotranspiration then search for the next discharge calculation debit mainstay of 99\% by the way of WEIBULL analysis water needs of domestic and non-domestic residents of Belitang district for 20 years analysing the quality of raw water by means by testing of water samples in situ and ex situ. The result of the test of quality, planned water supply system for district Belitang includes planning intakes) transmission pipelines and IPA building. Based on the result of the quality of raw water there are some parameters which is not appropriate with standard quality. Processing is 
necessary to adjust the water quality parameter is TSS, Ph, nitrate as $N$, iron and total coliform. The test results processing system used is coagulation, flocculation, sedimentation, filtration, and disinfection. The total need of clean water at peak hours of the district of Belitang in 2034 amounted to 0,03 $\mathrm{m}^{3} /$ second or 30 liter/second. Debit obtained from the calculation of the probability of $99 \%$ debit mainstay of $6,076 \mathrm{~m}^{3} /$ second and the result of measurable debit is in the field is $17,07 \mathrm{~m}^{3} /$ second. The kind of intake which is used is floating intake. Plan transmission pipe from the intake to the IPA building using a path length of drainage pipe with a planned 150 meters and a diameter is $200 \mathrm{~mm}$ with a HDPE pipe. The coagulation tub types which is used is hydraulic tub with waterfall and dimension of $1,2 \times 1,2 \times$ $1,2 \mathrm{~m}$. the flocculation tub is designed with gravitational energy source in the form of vertical channelshaped and tub dimension is $6 \times 2 \times 3 \mathrm{~m}$. sedimentation tanks is one with dimension 12,7 $\times 4,2 \times 3 \mathrm{~m}$. the filter which is used in this research is rapid sand filter with dimension $3,4 \times 1,7 \times 2 \mathrm{~m}$. the disinfectant which is used is chlorine for disinfection dimension 1,7 $\times 1,6 \times 1,6 \mathrm{~m}$. clean water reservoir capacity is $518,4 \mathrm{~m}^{3}$ with dimension $13,2 \times 13 \times 3 \mathrm{~m}$.

Keywords: clean water, the district of Belitang, availability of water, the quality of water.

\section{PENDAHULUAN}

Kecamatan Belitang merupakan satu dari tujuh kecamatan yang ada di Kabupaten Sekadau, jarak tempuh dari ibu kota Kabupaten Sekadau lebih kurang $75 \mathrm{Km}$ dan terdiri dari 7 Desa dan 18 Dusun. Kecamatan Belitang memiliki Sub DAS Belitang yang bermuara di DAS Kapuas. Berdasarkan studi identifikasi sumber air baku di Kabupaten Sekadau yang dilakukan pada tahun 2006 menyatakan bahwa potensi Sumber Air Baku (SAB) di Kecamatan Belitang sangat berlimpah karena Kecamatan Belitang berada di pinggiran Sungai Kapuas dan dikelilingi oleh sub DAS Belitang yang memiliki beberapa anak sungai di bagian hilirnya.

Kabupaten Sekadau memiliki sistem penyediaan air bersih yang terdapat di Kecamatan Nanga Taman yang menggunakan air baku mata air. Namun, untuk masyarakat Kecamatan Belitang Kabupaten Sekadau selama ini menggunakan air hujan, air permukaan (sungai) dan air sumur untuk memenuhi kebutuhan air bersih sehari-hari seperti memasak dan Mandi Cuci Kakus (MCK). Kondisi air sungai telah menurun kualitasnya akibat aktivitas di bantaran sungai, seperti aktivitas MCK yang menghasilkan limbah domestik, kegiatan pembukaan lahan untuk kegiatan perkebunan dan aktivitas lainnya.

Kecamatan Belitang memiliki sumber air baku yang melimpah, namun sampai saat ini belum tersedia fasilitas sarana sistem penyediaan air bersih. Untuk itu perlu kajian yang lebih mendalam terkait bagaimana kualitas air baku, proses pengolahan yang diperlukan serta bagaimana detail desain bangunan pengolahan air bersih yang sesuai untuk pengolahan air baku. Tujuan yang ingin dicapai dalam perencanaan ini yaitu untuk mengetahui aspek kualitas, kuantitas dan kontinuitas dari kebutuhan air baku Sungai Belitang untuk penyediaan air bersih bagi masyarakat Kecamatan Belitang. Serta merencanakan sistem penyediaan air bersih di Kecamatan Belitang yaitu intake, pipa transmisi dan bangunan Instalasi Pengolahan Air (IPA).

\section{METODOLOGI PERENCANAAN}

\section{A. Lokasi Perencanaan}

Perencanaan ini dilaksanakan di Kecamatan Belitang Kabupaten Sekadau, untuk sumber air yang ditinjau yaitu sumber air Sungai Belitang yang terletak di antara Desa Belitang Satu dan Desa Belitang dua Kecamatan Belitang Kabupaten Sekadau. 


\section{B. Pengumpulan Data}

Pengumpulan data yang dilakukan pada perencanaan ini dilakukan dengan dua metode yaitu observasi dan dokumentasi. Informasi yang dibutuhkan dalam perencanaan sistem penyediaan air bersih di Kecamatan Belitang Kabupaten Sekadau, serta tentang sumber air baku alternatif yang ditinjau yaitu sungai Belitang, data-data yang diperlukan, lokasi dan cara pengumpulan data ditampilkan pada Tabel 1.

Tabel 1. Pengumpulan Data-data yang Diperlukan dalam Perencanaan

\begin{tabular}{|l|l|l|l|l|}
\hline No & Nama Data & Jenis Data & Lokasi & Keterangan \\
\hline 1 & $\begin{array}{l}\text { Kondisi Masyarakat } \\
\text { Kecamatan Belitang }\end{array}$ & Primer & Kecamatan Belitang & Penyebaran Kuesioner \\
\hline 2 & Kualitas Air Baku & Primer & Sungai Belitang & Pengambilan Sampel \\
\hline 3 & Debit Air Baku & Primer & Sungai Belitang & $\begin{array}{l}\text { Pengukuran Luas Penampang } \\
\text { dan Kecepatan Aliran }\end{array}$ \\
\hline 4 & $\begin{array}{l}\text { Elevasi Rencana Trase } \\
\text { Pipa Transmisi }\end{array}$ & Primer & Kecamatan Belitang & Menggunakan GPS \\
\hline 5 & $\begin{array}{l}\text { Kondisi Eksisting Lokasi } \\
\text { Perencanaan Intake dan }\end{array}$ & Primer & Kecamatan Belitang & $\begin{array}{l}\text { Menggunakan GPS dan } \\
\text { Pengamatan Langsung }\end{array}$ \\
\hline 6 & Monografi Kecamatan & Sekunder & $\begin{array}{l}\text { Kantor Kecamatan } \\
\text { Belitang }\end{array}$ & $\begin{array}{l}\text { Jumlah Penduduk dan Fasilitas } \\
\text { Sarana Prasarana }\end{array}$ \\
\hline 7 & $\begin{array}{l}\text { Curah Hujan dan } \\
\text { Klimatologi }\end{array}$ & Sekunder & $\begin{array}{l}\text { Badan Wilayah } \\
\text { Sungai Kalimantan 1 }\end{array}$ & $\begin{array}{l}\text { Curah hujan, Jumlah Hari Hujan, } \\
\text { Suhu, Kelembaban Udara, } \\
\text { Kecepatan Angin Wilayah } \\
\text { Sekadau }\end{array}$ \\
\hline 8 & $\begin{array}{l}\text { Peta-peta } \\
\text { IPanatahari dan }\end{array}$ \\
\hline
\end{tabular}

\section{Analisis Data}

Analisis data diantaranya yaitu kebutuhan air bersih, kualitas air baku, ketersediaan air baku, letak dan jenis intake yang digunakan. Adapun hasil analisis yang didapatkan sebagai berikut:

\section{- Kondisi Masyarakat Kecamatan Belitang}

Menganalisis kondisi masyarakat Kecamatan Belitang yaitu berdasarkan hasil dari penyebaran kuesioner, dimana hasil analisis digambarkan menggunakan diagram pie. Analisis yang dilakukan mengetahui sikap, budaya, ekonomi dan keluhan kesehatan masyarakat Kecamatan Belitang.

\section{- Menganalisis Ketersedian Air Baku}

Menganalisis ketersedian air Sungai Belitang menggunakan analisis hidrologi yaitu analisis untuk mendapatkan besarnya debit andalan 99\% untuk menentukan base demand (dimana debit andalan ini dikompilasi dengan hasil analisis kebutuhan air penduduk). Analisis hidrologi meliputi analisis debit andalan cara Mock dan analisis debit andalan 99\%.

\section{- Menganalisis Kebutuhan Air}

Analisis kebutuhan air yang terbagi atas kebutuhan air domestik dan non domestik. Menganalisis kebutuhan air bersih dilakukan perhitungan proyeksi jumlah penduduk. Proyeksi jumlah penduduk menggunakan 3 metode yaitu: metode Aritmatika, Geometri dan Least Square. Hasil proyeksi dikalikan dengan standar kebutuhan air 


\section{- Menganalisis Kualitas Air Baku}

Sampel air yang diambil langsung di lokasi perencanaan dan diuji kualitasnya meliputi semua parameter berdasarkan PP nomor 82 tahun 2001 tentang pengelolaan kualitas air dan pengendalian pencemaran air di Laboratorium Sucofindo. Analisis kualitas air digunakan untuk mengetahui jenis pengolahan yang tepat sehingga menghasilkan air bersih yang sesuai dengan standar baku mutu air minum.

\section{Perencanaan}

Berdasarkan hasil analisis dilakukan perencanaan bangunan intake, perencanaan pipa transmisi dan perencanaan bangunan Instalasi Pengolahan Air (IPA).

\section{- Perencanaan bangunan intake}

Proses perencanaan bangunan intake terdiri dari elevasi dasar intake, elevasi pipa, menentukan jenis intake, serta dilakukan perhitungan mengenai jenis dan kapasitas pompa yang digunakan. Serta dilakukan perhitungan mengenai kehilangan energi akibat gesekan dan jenis pipa yang digunakan.

- Perencanaan Pipa Transmisi

Perencanaan pipa transmisi meliputi panjang pipa, jalur pipa, jenis pipa dan asesoris pipa yang digunakan.

- Perencanaan Bangunan IPA

Proses perencanaan IPA dan Reservoir terdiri dari menentukan letak IPA dan Reservoir, menentukan layout bangunan, menentukan urutan sistem pengolahan, menentukan jenis bangunan pengolahan, melakukan perhitungan hidrolik serta membuat gambar rancangan.

\section{E. Gambar Teknis}

Perencanaan dilakukan untuk mendapatkan gambar desain dari intake, profil memanjang dan profil melintang pipa transmisi, gambar masing-masing unit pengolahan, denah proses pengolahan dan gambar layout Instalasi Pengolahan Air (IPA).

\section{HASIL DAN PEMBAHASAN}

\section{A. Kondisi Masyarakat Kecamatan Belitang}

Penggambaran kondisi masyarakat Kecamatan Belitang dilakukan wawancara dengan penyebaran kuesioner yang bertujuan untuk mengetahui sikap, budaya, ekonomi dan keluhan kesehatan masyarakat Kecamatan Belitang. Sampel atau responden yang diambil dalam penyebaran kuesioner berjumlah 100 responden dengan metode acak. Responden yang diambil memiliki latar belakang umur, pendidikan, ekonomi dan anggota keluarga yang berbeda-beda. Data kondisi masyarakat masyarakat Kecamatan Belitang akan ditampilkan pada Gambar 1. 


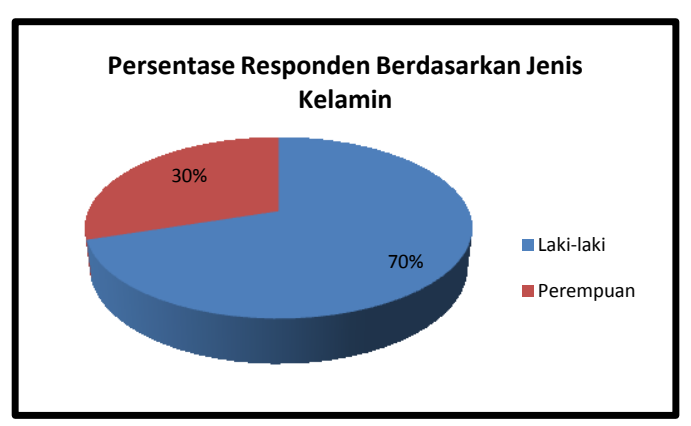

(a) Persentase Responden Bedasarkan Jenis Kelamin

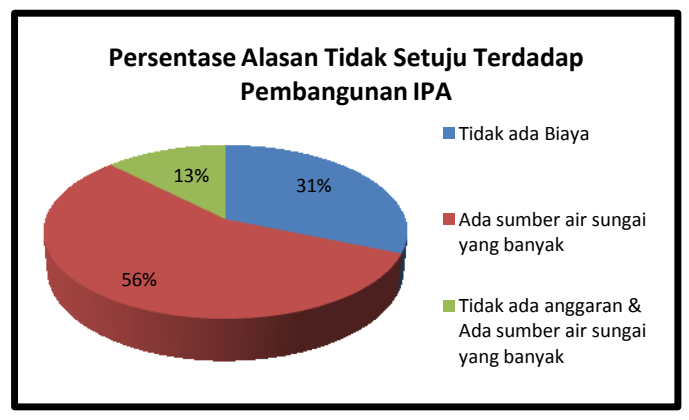

(c)Persentase Alasan Tidak Setuju dengan Pembangunan IPA

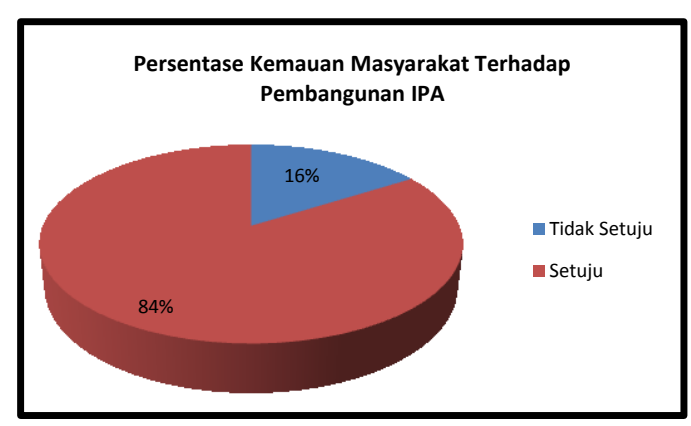

(b) Persentase Kemauan Masyarakat Terhadap pembangunan IPA

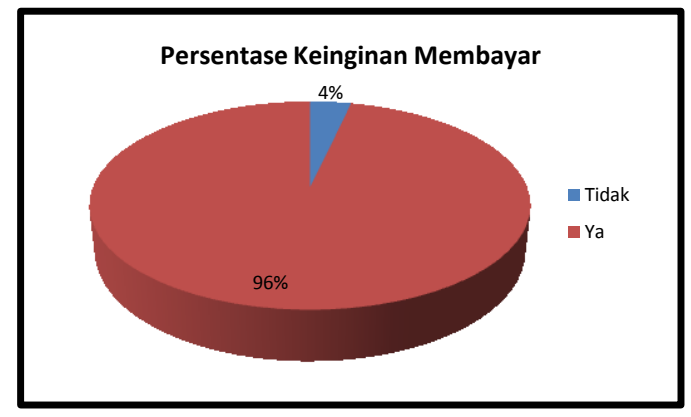

d) Persentase Keinginan Membayar

Gambar 1. Kondisi Masyarakat Kecamatan Belitang

Berdasarkan hasil survey wawancara kuesioner terhadap 100 responden sebesar $84 \%$ masyarakat setuju dengan pembangunan IPA dan 16\% masyarakat tidak setuju. Masyarakat yang setuju akan menggunakan air tersebut untuk keperluaan Mandi Cuci Kakus (MCK) dan keperluan memasak atau sumber air minum sebesar 52\%, untuk keperluaan memasak atau sumber air minum sebesar $41 \%$, dan untuk keperluaan Mandi CuCi Kakus sebesar 7\% dari total masyarakat yang setuju. Ada sekitar 4\% masyarakat tidak mau membayar dari $84 \%$ masyarakat yang setuju dengan pembangunan IPA yang berdasarkan kemampuan dan pendapatan per-bulan. Masyarakat yang tidak setuju dengan pembangunan IPA dikarenakan jumlah pendapatan per-bulan di bawah UMR dan masyarakat memilih menggunakan air sungai yang kualitasnya telah menurun.

\section{B. Analisis Ketersediaan Air Baku}

Berdasarkan hasil perhitungan menggunakan metode Mock yang memperhitungkan berdasarkan data curah hujan dan data klimatologi, diketahui bahwa debit terendah pada bulan Oktober yaitu sebesar 1,101 $\mathrm{m}^{3} /$ detik dan debit tertinggi pada bulan Desember yaitu sebesar $11,456 \mathrm{~m}^{3} /$ detik. Pengukuran debit lapangan dilakukan pada bulan Juni sebesar 17,07 $\mathrm{m}^{3} /$ detik. Grafik ketersediaan air baku Sungai Belitang dapat dilihat pada Gambar 2. 


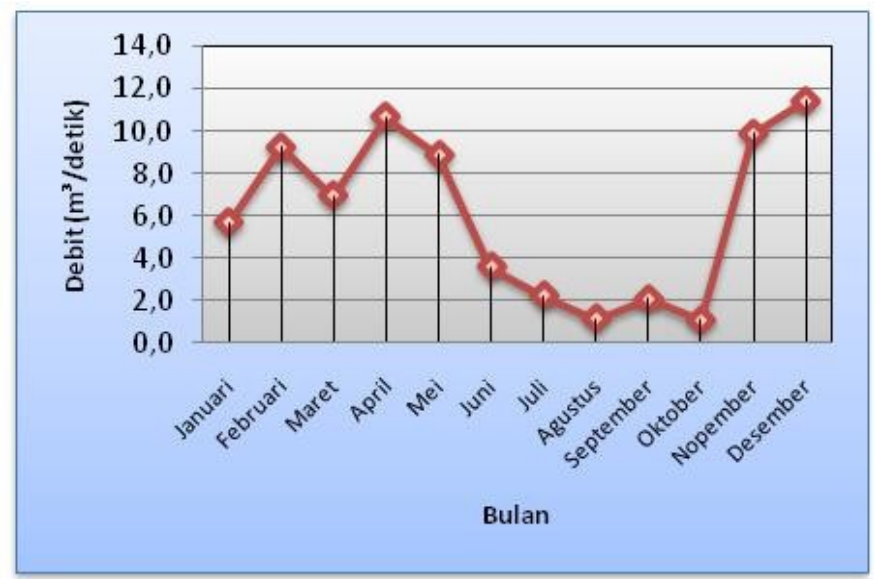

Gambar 2. Ketersedian Air Baku Sungai Belitang (Debit Andalan 99\%)

Dari gambar diatas maka didapatkan bahwa kuantitas dan kontinuitas air baku dapat terpenuhi sepanjang tahun dengan debit perhitungan Mock pada bulan Juni sebesar 3,602 $\mathrm{m}^{3} /$ detik.

\section{Analisis Kebutuhan Air Bersih}

Analisis kebutuhan air bersih di Kecamatan Belitang dilakukan dengan memproyeksikan pertumbuhan jumlah penduduk selama 20 tahun kedepan sesuai dengan umur tahun perencanaan. Jumlah penduduk diproyeksikan menggunakan tiga metode yaitu metode aritmatika, geometri dan least square. Ketiga metode ini selanjutnya diuji untuk mendapatkan metode yang akan digunakan untuk analisis kebutuhan air bersih. Berdasarkan nilai koefisien korelasi yang mendekati 1 dan nilai standar deviasi paling kecil metode geometri yang mendekati kebenaran. Jumlah proyeksi penduduk selama 20 tahun kedepan akan ditampilkan pada Gambar 3.

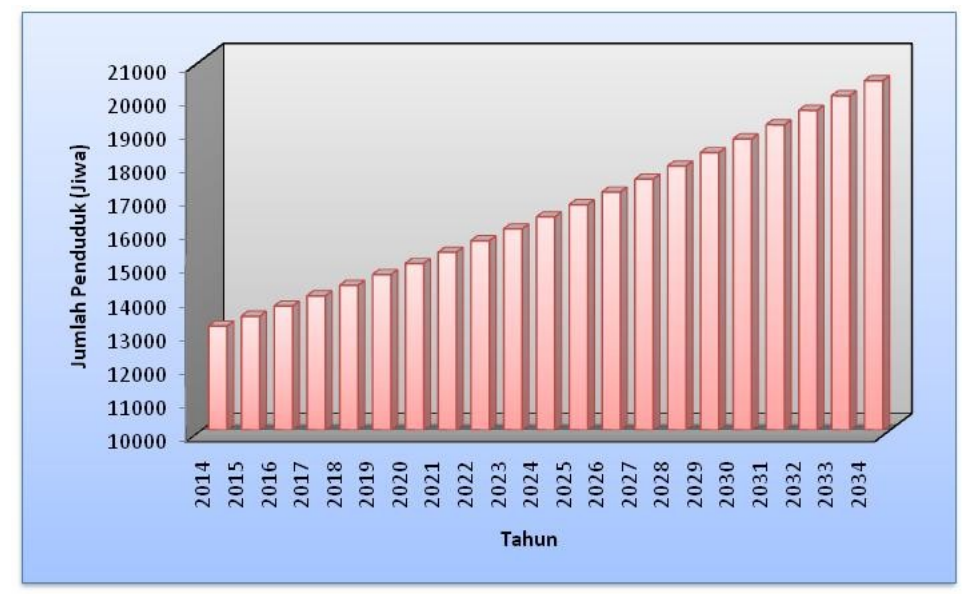

Gambar 3. Proyeksi Jumlah Penduduk 20 Tahun dengan Metode Geometri

Dari proyeksi penduduk 20 tahun selanjutnya dihitung kebutuhan air domestik dan kebutuhan non domestik. Kebutuhan air domestik meliputi kebutuhan air bersih untuk perumahan atau pemukiman bagi penduduk Kecamatan Belitang dengan cara Sambungan Rumah (SR) dan Hidran Umum (HU) yang diperhitungkan berdasarkan persentase jumlah penduduk yang akan dilayani dan untuk kebutuhan non domestik berdasarkan fasilitas umum yang ada di Kecamatan Belitang. Tabel 2 merupakan perhitungan jumlah kebutuhan air domestik dan non domestik. 
Tabel 2. Jumlah Kebutuhan Air Bersih di Kecamatan Belitang Selama 20 Tahun

\begin{tabular}{|l|l|l|l|l|l|l|}
\hline \multirow{2}{*}{ No } & \multirow{2}{*}{ Uraian } & Tahun & $\mathbf{2 0 3 4}$ \\
\cline { 3 - 7 } & & $\mathbf{2 0 1 4}$ & $\mathbf{2 0 1 9}$ & $\mathbf{2 0 2 4}$ & $\mathbf{2 0 2 9}$ & $\mathbf{2 0 3 4}$ \\
\hline 1 & Jumlah Penduduk & 13090 & 14624 & 16337 & 18251 & 20390 \\
\hline 2 & Persen Pelayanan & $50 \%$ & $60 \%$ & $70 \%$ & $80 \%$ & $90 \%$ \\
\hline 3 & Total Kebutuhan Domestik (Itr/detik) & 4,55 & 6,50 & 9,00 & 12,17 & 16,14 \\
\hline & $\begin{array}{l}\text { Total Kebutuhan Non Domestik } \\
\text { (Itr/detik) }\end{array}$ & 2,29 & 2,50 & 2,70 & 3,19 & 3,40 \\
\hline 5 & Total Kebutuhan Harian (Itr/detik) & 6,83 & 8,99 & 11,70 & 15,35 & 19,54 \\
\hline 6 & Kehilangan air 20\% & 1,37 & 1,80 & 2,34 & 3,07 & 3,91 \\
\hline 7 & Kebutuhan Harian (Itr/detik) & 8,20 & 10,79 & 14,05 & 18,43 & 23,45 \\
\hline 8 & $\begin{array}{l}\text { Kebutuhan Harian Maksimum (Qmd) } \\
\text { (Itr/detik) }\end{array}$ & 9,14 & 12,04 & 15,66 & 20,54 & 26,14 \\
\hline 9 & Kebutuhan Jam Puncak (Qp) (Itr/detik) & 10,25 & 13,49 & 17,56 & 23,03 & 29,31 \\
\hline 10 & Kebutuhan Jam Puncak (Qp) (m ${ }^{3} /$ detik) & 0,01 & 0,01 & 0,02 & 0,02 & 0,03 \\
\hline
\end{tabular}

Dari proyeksi tersebut didapatkan kapasitas pengolahan untuk merencanaan bangunan pengolahan air bersih. Kapasitas pengolahan yang digunakan dalam perencanaan ini yaitu menggunakan kapasitas jam puncak yaitu sebesar $30 \mathrm{l} /$ detik atau $0,03 \mathrm{~m}^{3} /$ detik. Kapasitas tersebut dapat memenuhi kebutuhan air bersih penduduk di Kecamatan Belitang selama 20 tahun kedepan (2015-2034).

\section{Analisis Kualitas Air}

Hasil uji kualitas sumber air baku Sungai Belitang Kecamatan Belitang yang dilakukan di Laboratorium Sucopindo pada bulan Juni 2015. Berdasarkan kualitas air baku, parameter yang akan diturunkan agar memenuhi standar baku mutu air bersih adalah TSS, pH, Nitrat sebagai $\mathrm{N}$, besi dan total coliform. Kadar kekeruhan, tingkat keasaman, kandungan nitrat, kandungan besi dan total coliform yang cukup tinggi. Menurut Joko (2010).

Berikut alternatif pengolahannya: koagulasi, flokulasi, sedimentasi, filtrasi dan desinfeksi. Prasedimentasi tidak dilakukan karena pada kualitas air baku nilai kekeruhan $120 \mathrm{mg} / \mathrm{l}$ atau 180 NTU. Menurut Joko (2010) untuk penggunakan bak prasedimentasi tingkat kekeruhan lebih dari 1000 NTU. Jadi alternatif yang digunakan pada perencanaan ini tidak menggunakan prasedimentasi dikarenakan mempertimbangkan aspek ekonomi dan efesien. Proses aerasi atau penambahan udara tidak dilakukan karena kadar besi kecil dan diperkirakan hilang pada proses koagulasi yang menggunakan proses hidrolis yaitu berbentuk terjunan, dalam proses terjunan tersebut kadar besi dapat teroksidasi oleh udara.

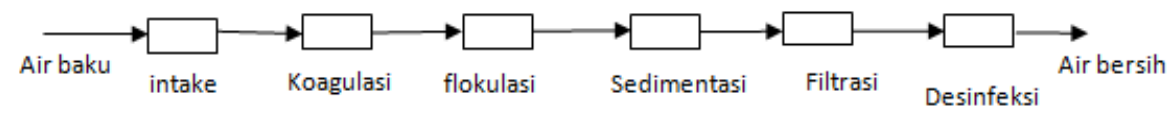

Gambar 4. Skema Proses Pengolahan 


\section{E. Perancangan Sistem Penyediaan Air Bersih}

Perencanaan sistem penyediaan air bersih di Kecamatan Belitang meliputi Perencanaan Intake, Pipa Transmisi, Bangunan IPA (Bak Koagulasi, Bak Flokulasi, Bak Sedimentasi, Bak Filtrasi, Bak Desinfeksi dan Reservoir). Gambar 5 berikut menggambarkan lokasi intake dan Bangunan Instalasi Pengolahan Air (IPA) yang direncanakan di Kecamatan Belitang Kabupaten Sekadau.

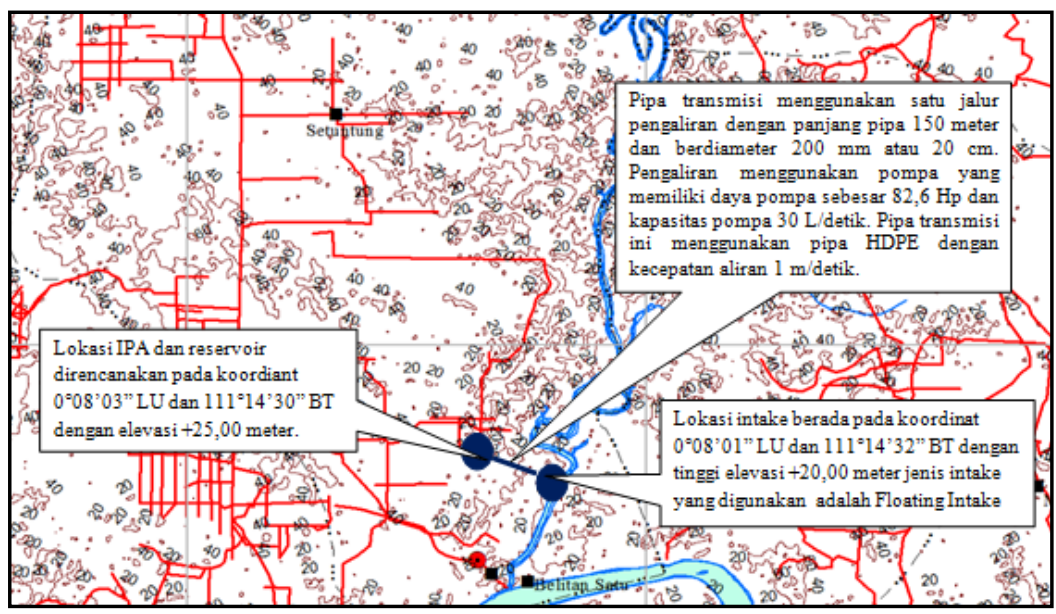

Gambar 5. Rencana Lokasi Intake dan Bangunan IPA

\section{- Intake}

Intake yang direncanakan yaitu Intake yang dapat menyesuaikan dengan fluktuasi kenaikan muka air, sehingga jenis Intake yang dipilih adalah Floating Intake. Letak intake berada pada elevasi +20 m sedangkan letak IPA berada pada elevasi +25 dengan jenis intake yang digunakan yaitu Floating Intake dan menggunakan pompa dengan daya 82,8 $\mathrm{Hp}$ dengan kapasitas pompa $30 \mathrm{~L} /$ detik.

\section{- Pipa Transmisi}

Rencana pipa transmisi dari Intake ke bangunan IPA menggunakan satu jalur pengaliran dengan panjang pipa 150 meter dan berdiameter $200 \mathrm{~mm}$ atau $20 \mathrm{~cm}$ memiliki ketebalan $22,4 \mathrm{~mm}$ dengan PN $16=16$ ATM/Bar $=160$ MKA. Pipa transmisi ini menggunakan pipa HDPE dengan kecepatan aliran $1 \mathrm{~m} /$ detik. Pipa akan ditanam di dalam tanah dengan pertimbangan agar tidak mendapatkan gangguan dari manusia, hewan dan cuaca yang dapat mempercepat rusaknya pipa. Kedalaman penanaman dihitung dari permukaan tanah terhadap bagian pipa yaitu sedalam $30 \mathrm{~cm}$.

\section{- Bak Koagulasi}

Perencanaan instalasi pengolahan air bersih Kecamatan Belitang akan dibangun satu unit bak koagulasi dengan debit rencana (Q) sebesar $0,03 \mathrm{~m}^{3} /$ detik. Bak koagulasi berbentuk persegi yang menggunakan pengadukan cepat tipe hidrolis dengan memanfaatkan energi yang terjadi dari tinggi terjunan air. Tipe hidrolis dengan terjunan dipilih dalam merencanakan bak koagulasi (pengadukan cepat) karena dapat menghemat biaya listrik dan debit pengolahan yang kecil diharapkan dapat mencampur bahan koagulan secara merata. Bahan koagulan yang digunakan aluminium sulfat $\mathrm{Al}_{2}\left(\mathrm{SO}_{4}\right)_{3}$ atau tawas. Tawas ini dipilih karena efektif sebagai pembentuk flok, mudah didapat di pasaran, murah, dan mudah larut dalam air secara sempurna. Demensi bak Koagulasi dengan $P$ x $L$ x T yaitu 1,2 $\times 1,2 \times 1,2$ meter. 


\section{- Bak Flokulasi}

Perencanaan instalasi pengolahan air bersih Kecamatan Belitang akan dibangun satu unit bak flokulasi dengan debit rencana (Q) sebesar $0,03 \mathrm{~m}^{3} /$ detik. Berdasarkan hasil perhitungan menggunakan kriteria desain bak flokulasi dengan pengadukan lambat menurut Darmasetiawan (2004) bak flokulasi (pengadukan lambat) didesain menggunakan sumber energi gravitasi berupa saluran berbelok-belok atau baffle chanel yang berbentuk vertikal dengan tujuan mempercepat proses pembentukan flok-flok yang merupakan penggabungan partikel tidak stabil sehingga terbentuk flok yang mudah mengendap dan untuk dimensi bak $6 \times 2 \times 3$ meter, dengan jumlah baffle sebanyak 6 buah dan chanel sebanyak 5 buah.

\section{- Bak Sedimentasi}

Perencanaan instalasi pengolahan air bersih Kecamatan Belitang akan dibangun satu unit bak sedimentasi dengan debit rencana (Q) sebesar $0,03 \mathrm{~m}^{3} /$ detik. Berdasarkan perhitungan mengunakan kriteria desain dari bak sedimentasi menurut Joko (2010), Bak sedimentasi berjumlah 1 buah dengan dimensi bak $12,7 \times 4,2 \times 3$ meter. $B$

\section{- Bak Filtrasi}

Filter yang digunakan dalam perencanaan ini menggunakan saringan pasir cepat dengan tebal lapisan pasir yang berdiameter $0,6 \mathrm{~mm}$ sebesar $70 \mathrm{~cm}$ dan tebal lapisan kerikil yang berdiameter $3 \mathrm{~mm}$ sebesar $30 \mathrm{~cm}$. Berdasarkan perhitungan menurut persamaan Kawamura (1991) Bak filtrasi berjumlah 2 buah dengan dimensi bak 3,4 x 1,7 × 2 meter.

\section{- Bak Desinfeksi}

Proses desinfeksi dalam perencanaan instalasi pengolahan air bersih Kecamatan Belitang akan digunakan desinfektan kimia berupa larutan kaporit. Berdasarkan kriteria desain perhitungan menurut Joko (2010) kebutuhan desinfektan sebesar 6,48 kg/hari dengan debit larutan kaporit yang digunakan sebesar 150,6 L/hari. Demensi bak pembubuh adalah $1,7 \times 1,6 \times 1,6$ meter.

\section{- Reservoir}

Kapasitas reservoir yang digunakan untuk menampung air bersih 30 liter/detik yaitu 518,4 $\mathrm{m}^{3}$ dengan dimensi $13,2 \times 13 \times 3$ meter.

\section{KESIMPULAN}

Berdasarkan hasil perhitungan dan analisis yang telah dilakukan dapat ditarik kesimpulan sebagai berikut:

a. Hasil uji kualitas air baku Sungai Belitang terlihat bahwa beberapa parameter yang tidak sesuai dengan baku mutu sebagai air baku dan air bersih. Oleh karena itu perlu dilakukan pengolahan untuk menurunkan atau menyesuaikan dengan baku mutu yaitu parameter TSS, $\mathrm{pH}$, nitrat sebagai $\mathrm{N}$, besi dan total coliform.

b. Ditinjau dari segi kuantitas, sumber air Sungai Belitang dapat mencukupi seluruh kebutuhan air bersih masyarakat Kecamatan Belitang. Total kebutuhan air bersih pada jam puncak penduduk Kecamatan Belitang Tahun 2034 sebesar $0,03 \mathrm{~m}^{3} /$ detik atau 30 liter/detik. Debit yang didapatkan dari perhitungan debit andalan probabilitas $99 \%$ sebesar $6,076 \mathrm{~m}^{3} /$ detik dan hasil debit terukur dilapangan sebesar $17,07 \mathrm{~m}^{3} /$ detik.

c. Ditinjau segi kontinuitas, dapat dikatakan bahwa sumber air ini selalu mengalir dan memenuhi kebutuhan air bersih sepanjang tahun. Berdasarkan hasil perhitungan dengan menggunakan metode Mock, diketahui bahwa debit terendah pada bulan Oktober yaitu sebesar 1,101 liter/detik dan debit tertinggi pada bulan Desember yaitu sebesar 11,456 liter/detik. 


\section{UCAPAN TERIMAKASIH}

Dengan selesainya perencanaan ini saya mengucapkan terima kasih yang sebesar-besarnya kepada Allah Swt, kedua orang tua, kedua dosen pembimbing yaitu Ibu Dr. Ir. Hj. Kartini, MT dan Ibu Laili Fitria, ST.,MT serta kepada teman-teman Teknik Lingkungan 2011 dan semua orang yang telah berperan dalam membantu penelitian yang tidak dapat di ucapkan satu persatu. Harapan saya perencanaan ini dapat bermanfaat bagi semua dan dapat dipergunakan sebagaimana mestinya.

\section{DAFTAR PUSTAKA}

Badan Pusat Statistik Kabupaten Sekadau. 2014. Sekadau Dalam Angka 2014. Sekadau.

Badan Wilayah Sungai Kalimantan 1. 2015. Data Curah Hujan dan Klimatologi untuk Dareah Sekadau dan Sekitarnya. Pontianak: BWSK 1.

Darmasetiawan. 2004. Teori dan Perencanaan Instalasi Pengolahan Air. Jakarta: Ekamitra Engineering

Ditjen Cipta Karya Depertemen Pekerjaan Umum. 2000. Kriteria Perencanaan Sektor Air Bersih. Jakarta.

Joko, T. 2010. Unit Produksi dalam Sistem Penyediaan Air Minum. Yogyakarta: Graha Ilmu.

Kawamura. 1991. Integrated Design of Water Trearment Facilities. New York: John Wiley \& Sons, Inc.

Mock, F.J.. 1973. Water Availability Appraisal in Indonesia (Land Capability Appraisal). Bacis Study Prepared for the FAO/UNDP Land Capability Appraisal Project. Bogor, Indonesia. 